\title{
Sequenciamento Adaptativo de Exercícios baseado na Correspondência entre a Dificuldade da Solução e o Desempenho Dinâmico do Aprendiz
}

\author{
Rômulo C. Silva ${ }^{1,2}$ (Autor), Alexandre I. Direne ${ }^{2}$ (Orientador) \\ ${ }^{1}$ Centro de Engenharia e Ciências Exatas (CECE) \\ Universidade Estadual do Oeste do Paraná (Unioeste), Foz do Iguaçu - PR \\ ${ }^{2}$ Departamento de Informática - Universidade Federal do Paraná (UFPR), Curitiba - PR \\ romulocesarsilvalgmail.com \\ alexdeinf.ufpr.br
}

\section{Resumo}

A perícia do aprendiz geralmente é desenvolvida através da resolução de exercícios que requerem um conjunto de habilidades avaliadas, tanto no sistema educacional de sala de aula convencional quanto em sistemas de apredizagem baseados em computador tais como Sistemas Tutores Inteligentes. Esta pesquisa propôs uma fórmula de rating para avaliação automática do desempenho do aluno, partindo-se do princípio de que o grau de dificuldade das questões pode ser medido pela taxa de alunos que as acertam/erram, sendo essa informação usada no cálculo de sua nota. Neste trabalho, os aspectos motivacionais em aprendizagem são considerados relevantes, sendo importante propor atividades adequadas ao nível da expertise do estudante, pois a apresentação de exercícios com grau de dificuldade muito abaixo (ou acima) do nível cognitivo do aprendiz pode causar entediamento (ou frustração), ocasionando o abandono da atividade proposta. Nesse sentido, este estudo também desenvolveu um algoritmo de sequenciamento adaptivo de exercícios que se baseia nos graus de dificuldade das questões, em que o sequenciamento é guiado pela performance dinâmica do aprendiz. Foi realizado um estudo empírico a partir de dados coletados de alunos reais que demonstrou a validade da fórmula de rating. Os algoritmos para cálculo do grau de dificuldades das questões e dos ratings dos alunos, bem como o algoritmo de sequenciamento adaptivo foram implementados efetuando-se alterações na ferramenta web de autoria de objetos de aprendizagem FARMA, gerando assim o ambiente ADAPTFARMA. Também foi realizada uma avaliação experimental da aprendizagem através de experimento estatístico comparativo entre diferentes modalidades de sequenciamento de exercícios usando como base um objeto de aprendizagem construído em ADAPTFARMA.

Referência (trabalho completo): Silva, R. C.; Direne, A. I.; Marczal, D.; Borille, A. C.; Guimarães, P. R. B.; Cabral, A. S.; Camargo, B. F. (2015). Um Arcabouço Adaptativo para Objetos de Aprendizagem. In Anais do XXVI Simpósio Brasileiro de Informática na Educação (SBIE 2015), Maceió-AL. 